\title{
KERUNTUHAN JEMBATAN AKIBAT KEGAGALAN PELAT BUHUL PADA SAMBUNGAN JEMBATAN RANGKA BAJA (Studi Kasus: Jembatan I-35W MISSISIPI)
}

\author{
Anis Rosyidah ${ }^{1}$ dan Johanes Adhijoso Tjondro² \\ ${ }^{1}$ Politeknik Negeri Jakarta (PNJ), Jl. Prof. GA. Siwabessy Kampus UI Depok \\ ${ }^{2}$ Universitas Katholik Parahyangan Bandung, Jl. Ciumbuleuit no. 94 Hegarmanah Bandung \\ Email: ${ }^{1}$ anis.rosyidah@gmail.com
}

\begin{abstract}
The collapse of Minnesota Bridge number 9340 or I-35W bridge on August 1, 2007, is indeed surprising considering the maintenance of the bridge conducted regularly. The bridge was designed in the early 1960s using AASHO "Standard Specification for Highway Bridges" 1961 edition with the allowable stress method. Materials used HSLA (high-strength low-alloy) steel. The data on the I-35W bridge obtained from the NTSB (National Transportation Safety Board) report. The analysis to identify the cause of the collapse of the I-35W bridge derived from the results of a review of previous research.

The method of analysis referred to is a simple method of Holt and Hartman (2008), FEM by Hao (2010), Liao (2010), and Lora (2013).

The finding of the I-35W bridge indicates that the cause is due to the lack of U10 gusset plate capacity, because the thickness of the gusset plate at the joint is the other thinnest gusset plate and its failure due to buckling, and the condition of the gusset plate has been deformation in the construction period. The further adds a substantial buckling.

The result of evaluation using simple and FEM method proves that the gusset plate capacity of the U10 joint is inadequate so that the gusset plate overstressed. The collapse pattern of the gusset plate at the U10 joint has similarities between the analysis with FEM and the damage of the real bridge.
\end{abstract}

Keyword: Steel truss bridge, joint, gusset plate

\begin{abstract}
ABSTRAK
Keruntuhan jembatan Minnesota no. 9340 atau jembatan I-35W pada 1 Agustus 2007 sangat mengejutkan mengingat perawatan jembatan ini dilakukan teratur secara berkala. Jembatan ini didesain pada awal tahun 1960an menggunakan peraturan AASHO "Standard Specification for Highway Bridges" edisi 1961 dengan metode tegangan ijin. Material yang digunakan baja mutu tinggi HSLA (high-strength low-alloy). Data-data mengenai jembatan I-35W diperoleh dari laporan NTSB (National Transportation Safety Board). Sedangkan analisis untuk mengidentifikasi penyebab keruntuhan jembatan I-35W diperoleh dari hasil kajian dari penelitian terdahulu. Metode analisis yang diacu adalah metode sederhana dari Holt dan Hartman (2008), metode FEM oleh Hao (2010), Liao (2010), dan Lora (2013).

Hasil analisis terhadap keruntuhan jembatan I-35W menunjukkan bahwa penyebab keruntuhan disebabkan kapasitas pelat buhul U10 yang kurang karena ketebalan pelat buhul pada sambungan tersebut paling tipis dibanding pelat buhul yang lain dan keruntuhannya akibat tegangan tekuk yang besar, serta kondisi pelat buhul sudah mengalami deformasi pada saat masa pengkonstruksian. Hal ini makin menambah tekuk yang besar.

Hasil evaluasi dengan metode sederhana maupun FEM membuktikan bahwa kapasitas pelat buhul pada sambungan U10 tidak memadai sehingga pelat buhul mengalami overstress. Pola keruntuhan pelat buhul pada sambungan U10 mempunyai kesamaan antara analisis dengan FEM dengan kerusakan jembatan aslinya.
\end{abstract}

Kata Kunci: Jembatan rangka baja, sambungan, pelat buhul

\section{PENDAHULUAN}

Peristiwa runtuhnya jembatan I-35W Missisipi telah menyadarkan para enjiner arti pentingnya pelat gusset pada perancangan jembatan. Jembatan I-35W Missisipi ini memang sudah cukup lama dibangun hampir 50 tahun yang lalu. Dugaan awal penyebab keruntuhannya adalah korosi, setelah dilakukan penelitian yang mendalam ternyata terjadi fraktur pada plat simpul atau gusset. Dalam merancang sambungan selama ini lebih 
berfokus pada kekuatan komponen batang, perancangan gusset hanya sebagai pelengkap, yang penting tebalnya minimal sama dengan tebal plat yang disambung. Jembatan rangka yang serupa dengan jembatan I-35W Missisipi banyak terdapat di Indonesia. Data dari PU jembatan rangka di Indonesia sekitar 22\% dari jumlah jembatan yang ada. Kemungkinan kejadian runtuhnya gusset tersebut dapat pula terjadi di Indonesia sehingga kejadian runtuhnya jembatan I-35W Missisipi ini menarik untuk dikaji terkait dengan kegagalan gusset tersebut. Ada yang melakukan investigasi, survey, analisis sederhana, analisis makro sampai analisis mikro yang kompleks menggunakan Finite element method (FEM). Pelat buhul ini sampai runtuh tentu ada sebabnya. Dalam studi ini dilakukan kajian mengenai pemicu kegagalan pelat buhul menggunakan data hasil-hasil penelitian terdahulu.

\section{Gusset Plate (Pelat Buhul)}

Telah banyak penelitian mengenai kekuatan dan perilaku sambungan pelat buhul baik untuk obyek pada bangunan gedung maupun jembatan. Terdapat perbedaan yang mendasar sambungan pelat buhul pada jembatan dibanding gedung yaitu (a) menerima beban fatik, (b) menggunakan pelat buhul ganda, (c) dirancnag dalam kondisi elastis, sedangkan pada gedung pelat buhul didesain untuk menahan beban gempa hingga kondisi inelastis.

Cara mendapatkan kekuatan tekuk pelat buhul akibat gaya tekan Thornton (1984) menyarankan penggunaan lebar whitmore dan rata-rata panjang pelat tanpa pengekang [1]. Yam (1993) mengembangkan metode Thornton untuk mengestimasi kapasitas tekuk dengan redistribusi beban yang menyebabkan kelelehan pelat buhul sebelum terjadi keruntuhan [2]. Penyebaran tegangan modifikasi metode Thornton menggunakan sudut 45․ Yoo (2006) [3] mengumpulkan data tekuk pada pelat buhul dan digunakan untuk memprediksi tekuk pada pelat buhul. Penggabungan metode Thornton dan modifikasi dengan sudut penyebaran tegangan sebesar $45^{\circ}$ dan rata-rata ketiga panjang tanpa pengekang, dikenal dengan metode Yoo.

\section{Asesmen Cepat Pengecekan Kekuatan Pelat Buhul}

Jumlah pelat buhul sebuah jembatan dapat mencapai puluhan hingga ratusan. Apabila asesmen terhadap pelat buhul ini rumit dan komplek maka pemeriksaannya memerlukan waktu yang cukup lama. Beberapa metode asesmen telah dibuat, antara lain olehFederal Highway Administration (FHWA). Peneliti lain yang melakukan asesmen menggunakan simulasi numerik dengan FEM adalah Berman [4][5]. Teori Berman disebut metode TEP (Triage Evaluation Procedure) (Gambar 2.8).Tinjauannya meliputi 2 poin evaluasi terkait dengan pelat buhul yaitu (1) kelelehan pelat buhul dan (2) tekuk pelat buhul, serta 1 tinjauan mengenai alat sambung. Kelelehan pelat buhul tidak serta merta menyebabkan struktur jembatan langsung runtuh. Namun dapat memicu kerusakan struktur yang sangat fatal. Untuk kontrol tegangan maksimum dapat menggunakan lebar efektif Whitmore. Gambar 1 menunjukkan batang diagonal yang tersambung dengan pelat buhul dan distribusi tegangan yang terjadi.

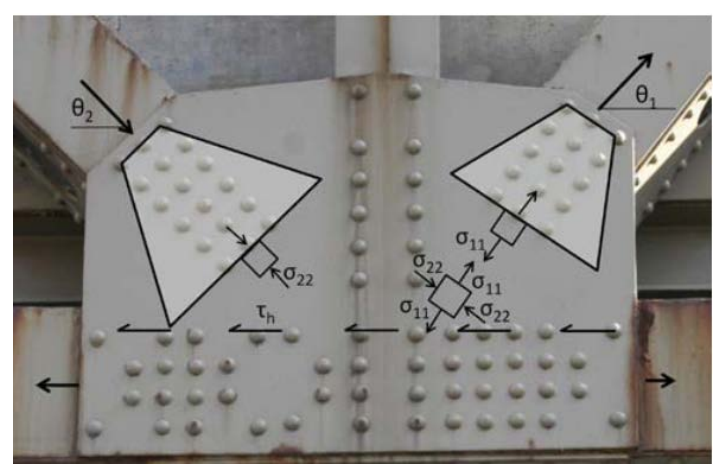

Gambar 1. Tegangan pada pelat buhul [6]

\section{METODA PENELITIAN}

Deskripsi Jembatan 
Jembatan Minnesota no. 9340 atau lebih dikenal dengan jembatan I-35W didesain oleh konsultan struktur Sverdrup \& Parcel untuk Minnesota Department of Transportation (Mn/DOT) pada awal tahun 1960an. Truss utama memiliki 3 bentang dengan kedua ujung kantilever (Gambar 2). Jembatan tersebut memiliki 14 bentang yang disokong oleh 13 pier dan 2 abutment [7]. Peraturan yang digunakan adalah AASHO "Standard Specification for Highway Bridges" edisi 1961 dengan metode tegangan ijin [8]. Hampir semua data mengenai perencanaan, pembebanan, spesifikasi material, dan gambar kerja tersedia dan dapat diperoleh dari Mn/DOT [9].

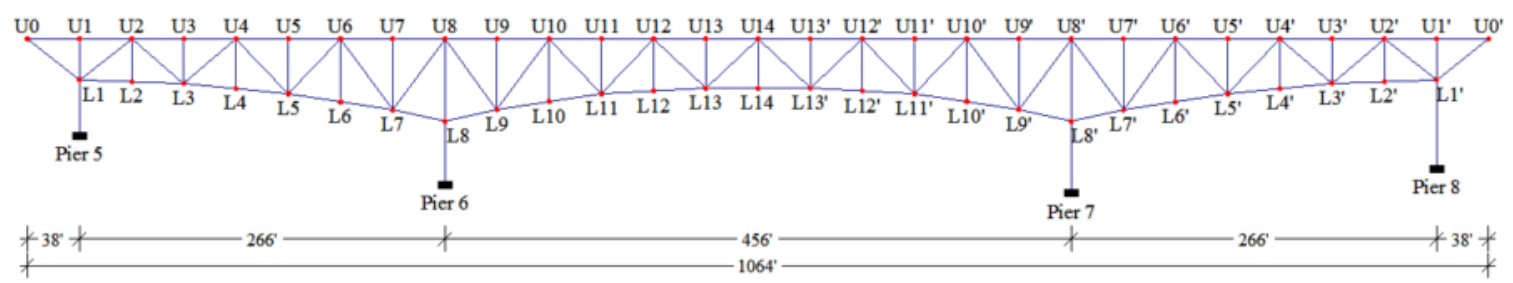

Gambar 2. Bentuk Truss Utama Jembatan I-35W [10]

Jembatan ini menggunakan material baja mutu tinggi HSLA (high-strength lowalloy)termasuk pelat buhul yang didesain dengan tegangan ijin. Tegangan tersebut tergantung dari tebal mateial dan arah gaya. Terdapat pelat buhul dengan ketebalan kurang dari $3 / 4$ inchi yang digunakan pada titik buhul U10 dan L11. Data tegangan ijin yang digunakan untuk assesment antara lain: (a) tegangan tarik = 27.000 psi, (b) tegangan geser $=15.000$ psi, (c) tegangan tekan $=22.000 \mathrm{psi}-$ $0,56(\mathrm{~L} / \mathrm{r})^{2}$. Dimana L adalah panjang pelat buhul tanpa pengekang, dan $r$ merupakan jari-jari girasi profil.

Dokumen desain perhitungan asli oleh Sverdrup \& Parcel untuk Jembatan I-35W yang diperoleh dari Mn / DOT ternyata tidak ada informasi mengenai desain sambungan pelat buhul. Oleh karena itu tidak memungkinkan untuk memeriksa kebenaran perhitungan asli pelat buhul di truss utama. Selanjutnya acuan untuk mengevaluasi kekuatan pelat buhul mengikuti peraturan yang digunakan untuk perancangan truss utama yaitu AASHO [8].

Pembebanan yang diperhitungkan untuk evaluasi pelat buhul meliputi beban mati, beban hidup, dan beban impact. Pembebanan tersebut sama dengan yang digunakan oleh konsultan Sverdrup \& Parcel dalam menentukan gaya-gaya batang dalam perancangan struktur.Beban mati terdiri dari berat struktur serta komponen-komponennya dan beban mati tambahan terdiri dari dek jembatan, trotoar, dan pagar pembatas. Beban hidup yang digunakan untuk desain dengan tipe kendaraan H20-S16-44. Lebar jembatan terdiri dari 2 lajur, masing-masing lajur ada 7 jalur. Bentuk melintang jembatan setengah bentang disajikan pada Gambar 2.Untuk mengakomodir beban hidup yang bergerak juga diperhitungkan beban impact sebesar $9 \% \quad$ - $13 \%$. 


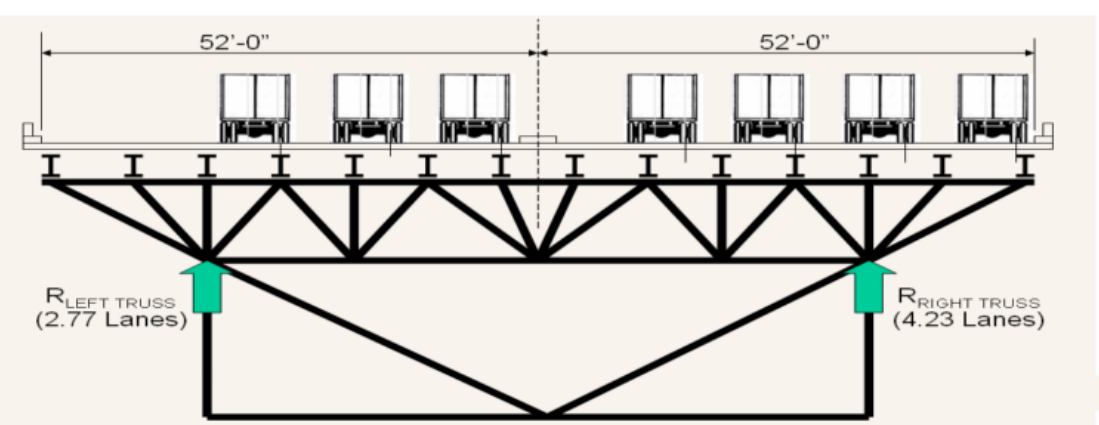

Gambar 2. Penempatan beban hidup untuk desain [8]

Data-data mengenai jembatan I-35W diperoleh dari laporan NTSB (National Transportation Safety Board). Sedangkan analisis untuk mengidentifikasi penyebab keruntuhan jembatan I-35W diperoleh dari hasil kajian dari penelitian terdahulu. Metode analisis yang diacu adalah metode sederhana dari Holt dan Hartman [8] dan metode FEM oleh Hao (2010), Liao (2010), dan Lora (2013).

\section{HASIL DAN PEMBAHASAN}

Dugaan awal keruntuhan jembatan adalah akibat korosi,mengingat jembatan ini sudah cukup lama beroperasi dan dari beberapa dokumentasi terdapat korosi pada jembatan tersebut.Setelah diteliti ternyata keruntuhannya adalah akibat kegagalan pada pelat buhul.Pelat buhul sering dianggap tidak penting ketika merencanakan sambungan suatu struktur. Perencanaan sambungan dianggap selesai dan aman hanya dengan melakukan pengecekan terhadap alat sambung menggunakan las atau baut. Selanjutnya jika pelat buhul dipastikanlebih tebal atau minimal sama dengan tebal profil yang disambung maka sambungan tersebut dinyatakan aman. Dalam dokumen perencanaan jembatan I-35W sendiri perhitungan pelat sambung tidak ada di dalamnya[8]. Ini menunjukkan bahwa desain pelat buhul itu tidak terlalu penting dan ada anggapan bahwa pelat buhul itu adalah urusan detail fabrikasi[11].

Ambruknya jembatan I-35W menarik perhatian para peneliti untuk melakukan riset, mulai dengan metode sederhana sampai yang rumit menggunakan Finite Element Analysis. Pada tahun 2003 jembatan I-35W ini dilakukan monitoring, terdapat foto-foto detail jembatan termasuk sambungan pelat buhul. Dari situ pula ditemukan bahwa pada join U10 tampak pelat buhul melengkung (Gambar $3)$.

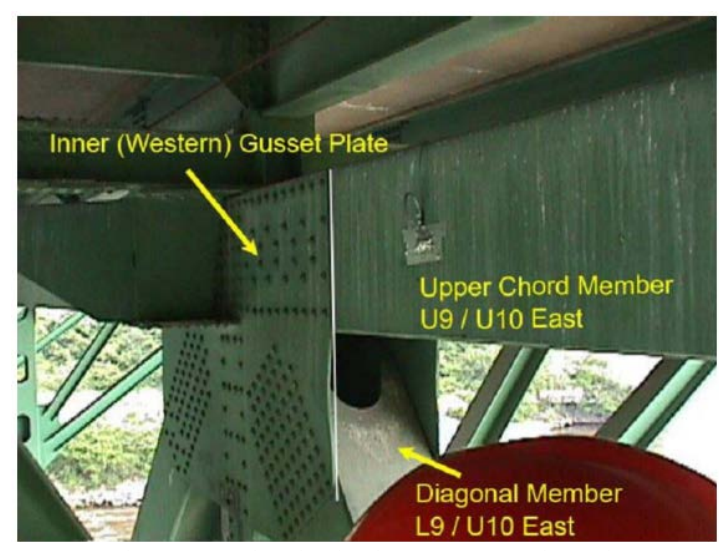

Gambar 3 Pelat buhul U10E melengkung Sumber: NTSB [7]

Melengkungnya pelat buhul ditemukan justru pada waktu jembatan sudah runtuh. Fakta ini menarik, apabila jembatan dianggap selalu dalam kondisi terawat seharusnya pelat buhul yang melengkung dapat diketahui jauh sebelum jembatan roboh. Ternyata kondisi melengkung ini sudah terjadi sejak jembatan ini saat masa konstruksi, sebab tidak ada tanda-tanda retak pada cat pelapis akibat deformasi yang berlebihan.

Hasil pengamatan di lapangan, keruntuhan jembatan I-35W disebabkan titik buhul pada U10W dan U10E mengalami keruntuhan fraktur. Pola keruntuhan jointersebut terjadi pada ke-2 sisi rangka dan menunjukkan pola yang sama (Gambar 4).Garis biru pada Gambar 4 
menunjukkan pola keruntuhan fraktur. Sedangkan wujud titik buhul U10 yang

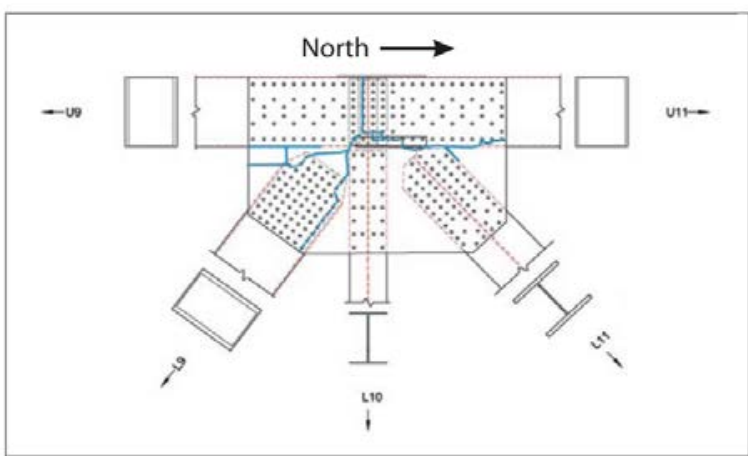

a. Join U10W dari sisi dalam arah selatan telah runtuh dapat dilihat pada Gambar 5.

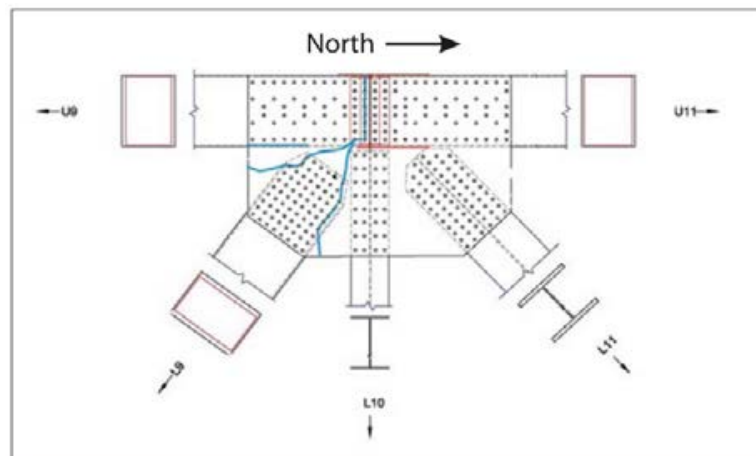

b. Join U10E dari sisi luar arah selatan

Gambar 4. Pola keruntuhan pelat buhul U10W dan U10E (sumber: NTSB [7])

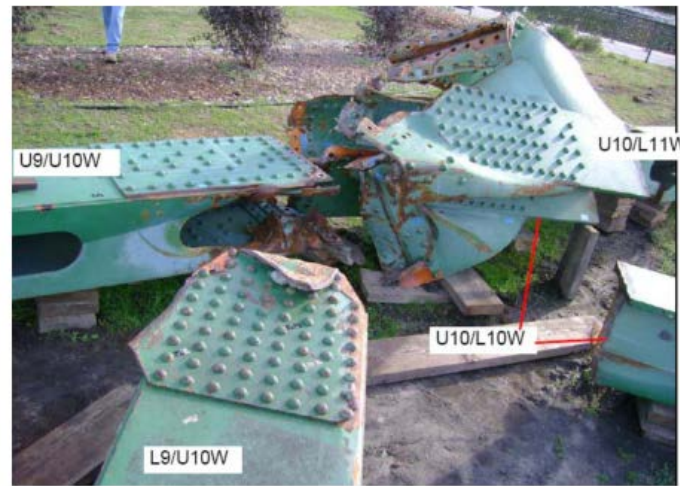

(a) Photograph of U10W (from NTSB 2008a)

Gambar 5. Foto titik buhul U10 setelah jembatan runtuh (sumber: NTSB [7])

Kerusakan titik buhul ini diduga akibat kegagalan pelat buhul. Hal ini didukung dengan fakta yang menunjukkan bahwa pelat buhul pada U10 tersebut memiliki ketebalan yang relatif lebih tipis dibanding pelat buhul yang lain. Tebal pelat buhul yang digunakan pada jembatan I-35W ditampilkan pada Gambar 6.

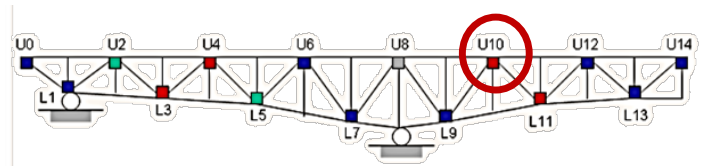

Legend:

口 $13 / 8$ " thick gusset plate (100 ksi)

- 1 " thick gusset plate (50 ksi)

- $5 / 8$ " thick gusset plate ( $50 \mathrm{ksi})$

- $1 / 2$ " thick gusset plate $(50 \mathrm{ksi})$

Gambar 6. Ketebalan pelat buhul yang digunakan pada jembatan I-35W

Sumber: Holt [8]

\section{Evaluasi Pelat buhul Jembatan I-35W}

Holt dan Hartman (2008)[8] melakukan evaluasi sederhana untuk membuktikan kebenaran dugaan awal bahwa keruntuhan jembatan I-35W itu disebabkan oleh kegagalan dari pelat buhul.Berbagai fakta telah ditemukan mulai dari foto pelat buhul yang melengkung dan dari gambar dokumentasi juga ditemukan tebal pelat buhul pada joint U10 lebih tipis dari pelat buhul yang lain. Ada dugaan juga telah terjadi kesalahan dalam desain pelat buhul, namun tidak ditemukan dokumen perencanaan pelat buhul tersebut sehingga tidak dapat dievaluasi kebenarannya. Ada kemungkinan pelat buhul tidak dihitung kekuatannya sebab ada anggapan bahwa pelat buhul itu tidak berperan dalam kinerja struktur.

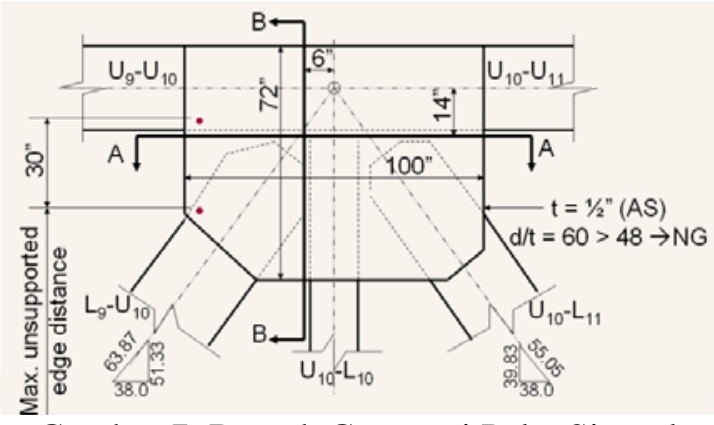

Gambar 7. Bentuk Geometri Pelat Simpul U10 [8]

Evaluasi sederhana yang dilakukan Holt dan Hartman dapat memprediksi kinerja pelat buhul. Bentuk geometri titik buhul U10 seperti pada Gambar 7. Jika 
diperhatikan panjang tepi pelat buhul sisi kanan yang terbuka tanpa stiffener > $48 \times$ tebal pelat buhul, ini tidak sesuai dengan peraturan AASHO 1961. Seharusnya pelat buhul sepanjang itu tersebut diberi setiffener[8][11].

Tegangan yang terjadi pada pelat buhul tersebut selanjutnya dibandingkan dengan kekuatan ijin dari pelat buhul berdasarkan
AASHO 1961. Hasilnya berupa rasio tegangan yang terjadi terhadap tegangan ijin pelat buhul. Apabila nilai rasio lebih dari 1 berarti tebal pelat buhul tidak mencukupi, tetapi jika kurang dari 1 berarti OK. Tabel 1 menyajikan hasil perhitungan tegangan pada pelat buhul U10.

Tabel 1. Rasio tegangan potongan A-A dan B-B pelat buhul U10 [8]

\begin{tabular}{cccccc}
\multirow{2}{*}{$\begin{array}{c}\text { Jenis } \\
\text { Tegangan }\end{array}$} & $\begin{array}{c}\text { Tegangan Ijin } \\
\text { AASHO 1961 (ksi) }\end{array}$ & $\begin{array}{c}\text { Potongan A-A } \\
\text { Tegangan } \\
\text { (ksi) }\end{array}$ & Rasio & $\begin{array}{c}\text { Tegangan } \\
\text { (ksi) }\end{array}$ & Rasio \\
\hline Lentur & $27\left(0.54 \mathrm{~F}_{\mathrm{y}}\right)$ & 22.9 & 0.85 & 17.0 & 0.63 \\
Geser & $15\left(0.30 \mathrm{~F}_{\mathrm{y}}\right)$ & 27.2 & $\mathbf{1 . 8 1}$ & 25.5 & $\mathbf{1 . 7 0}$ \\
Tarik & $27\left(0.54 \mathrm{~F}_{\mathrm{y}}\right)$ & 41.6 & $\mathbf{1 . 5 4}$ & 39.5 & $\mathbf{1 . 4 6}$ \\
Tekan & $22\left(0.44 \mathrm{~F}_{\mathrm{y}}\right)$ & 40.3 & $\mathbf{1 . 8 3}$ & 37.1 & $\mathbf{1 . 6 9}$ \\
\hline
\end{tabular}

Tabel 1 menunjukkan rasio tegangan geser, tarik dan tekan lebih besar dari 1 baik pada potongan A-A maupun B-B, ini menunjukkan bahwa pelat buhul U10 dengan tebal pelat $1 / 2$ in kapasitasnya kurang. Dibanding dengan pelat buhul yang lain, tegangan yang terjadi pada titk buhul U10 relatif lebih besar tetapi tebal pelat buhul yang digunakan justru paling kecil.

Tegangan pada titik buhul tersebut belum menunjukkan tegangan maksimum pada waktu jembatan runtuh. Mengingat analisis yang dilakukan dengan metode elastis linier sehingga tidak dapat dipakai untuk menganalisis perilaku non-linier. Untuk memprediksi perilaku penyebab keruntuhan jembatan dapat dilakukan analisis non linier. Hao (2010) [12] melakukan simulasi numerik secara makro dengan membuat pemodelan jembatan secara utuh. Selain analisis makro juga dilakuk ananalisis mikro dengan memodelkan secara detail bagian yang dianggap kritis.

Hao mendapatkan hasil analisis secara makrosama dengan yang ditemukan oleh Holt (2008), yaitu pelat buhul U10 mengalami overstress. Demikian juga Liao (2010) [13] dan Lora (2013) [10] telah melakukan analisis menggunakan FEM dan diperoleh hasil yang sama pula.
Analisis FEM diharapkan dapat memprediksi perilaku keruntuhan pelat buhul dengan menganalisis secara nonlinier dari material dan geometri. Pembebanan juga dapat dilakukan secara bertahap sehingga tahapan perubahan tegangan menjelang runtuh dapat diidentifikasi. Gambar 8 merupakan tahapan analisis tegangan pelat buhul U10 menggunakan FEM oleh Liao, terdapat kecocokan pola keruntuhan yang terjadi pada jembatan I-35W yang disajikan dalam Gambar 4.

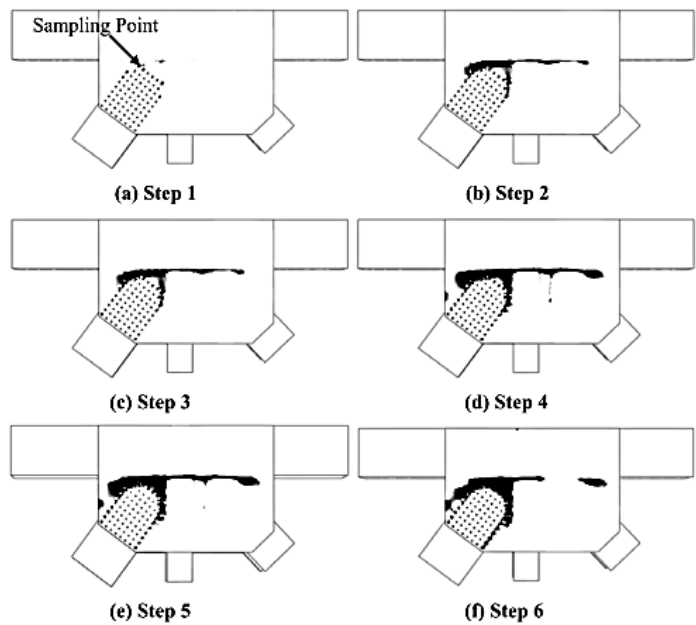

Gambar 8. Tahapan proses kelelehan pada pelat buhul (Liao: 2010)

Lora (2013) juga melakukan analisis linier pelat buhul U10, hasil yang didapat adalah 
mode 1 dari pelat buhul ini mengalami buckling ke sisi luar bidang, seperti pada Gambar 7. Ini menunjukkan bahwa kondisi terlemah dari pelat buhul jika menerima beban melebihi kapasitasnya akan terjadi buckling.

Penelitian Lora (2013) dilanjutkan dengan menganalisis non linier, pelat buhul pada kondisi awal atau pada waktu pengkonstruksian dimodelkan sudah terjadi deformasi. Pelat buhul diberi pembebanan bertahap, beban saat pengkonstruksian, beban service, dan beban maksimum sehingga dapat diketahui tegangan dan deformasi menjelang runtuh. Kesimpulan dari analisis Lora adalah terdapat kemiripan pola deformasi antara hasil analisis menggunakan FEM dengan dokumentasi deformasi jembatan sebelum runtuh. Sebaran tegangan hasil analisis dengan FEM juga menunjukkan pola yang sama dengan keruntuhan jembatan I-35W.

\section{KESIMPULAN}

Hasil analisis terhadap keruntuhan jembatan I-35W menunjukkan bahwa penyebab keruntuhan disebabkan kapasitas pelat buhul U10 yang kurang karena ketebalan pelat buhul pada sambungan tersebut paling tipis dibanding pelat buhul yang lain dan keruntuhannya akibat tegangan tekuk yang besar, serta kondisi pelat buhul sudah mengalami deformasi pada saat masa pengkonstruksian. Hal ini makin menambah tekuk yang besar.

Hasil evaluasi dengan metode sederhana maupun FEM membuktikan bahwa kapasitas pelat buhul pada sambungan U10 tidak memadai sehingga pelat buhul mengalami overstress.Pola keruntuhan pelat buhul pada sambungan U10 mempunyai kesamaan antara analisis dengan FEM dengan kerusakan jembatan aslinya.

\section{DAFTAR PUSTAKA}

[1] A. Astaneh-Asl. 2008. "Progressice collapse of steel truss bridges, the case of I-35W collapse," 7th Int. Conf. Steel Bridg., pp. 4-6.

[2] Barry B. LePatner. 2010. "The Story Behind the Collapse of Minnesota, s I-35W Bridge on," Univ. New Engl. Press, no. Too Big to Fall: America's Failing Infrastructure and the Way Forward.

[3] Bo Dowswell. 2005. "Gusset plate stress,” Thesis, pp. 1-21..

[4] Davis C.S. 1967. "Computer Analysis of the Stresses in a Gusset Plate,” Thesis, vol. University, p. in partial fulfillment of the requirements for the, 1967.

[5] F. I. S. Ibrahim. 2009. "Load Rating Guidance and Examples For Bolted and Riveted Gusset Plates In Truss Bridges," U.S. Dep. Transp. Fed. Highw. Adm., no. February, 2009.

[6] Hardin B.O. 1958. "Experimental Investigation of the Primary Stress Distribution in the Gusset Plates of a Double Plane Pratt Truss Joint with Chord Splice at the Joint," Thesis, vol. University, no. Bulletin No. 49, 1958.

[7] Irvan W.G. 1957. "Experimental Study of Primary Stresses in Gusset Plate of a Double Plane Pratt Truss," Bull. No. 49, no. University of Kentucky Engineering Experiment Station.

[8] J.-H. Yoo, C. W. Roeder, and D. E. Lehman. 2008. "Analytical Performance Simulation of Special Concentrically Braced Frames," J. Struct. Eng., vol. 134, no. 6, pp. 881-889, 2008.

[9] J. W. Berman, A. M. Asce, B. Wang, S. M. Asce, A. W. Olson, C. W. Roeder, M. Asce, and D. E. Lehman. 2012. "Rapid Assessment of Gusset Plate Safety in Steel Truss Bridges,” J. Bridg. Eng., vol. 17, no. April, pp. 221-231, 2012.

[10] J. W. Berman, C. W. Roeder, B. Wang, A. W. Olson, D. E. Lehman, N. E. Street, H. Coffman, W. Olson, P. Manager, and R. Brooks. 2010. 
"TRIAGE EVALUATION OF GUSSET PLATES IN STEEL TRUSS BRIDGES,” no. December, 2010.

[1] W. A. Thornton, "Bracing

Connections for Heavy Construction,” Eng. Journal, AISC, vol. 21, no. 3, pp. 139-148, 1984.

[2] Michael C.H. Yam and J.J. Roger Cheng, Experimental Investigation of The Compressive Behavior of Gusset Plate Connections.

Edmonton, Alberta, Canada: Department of Civil Engineering, The Univesity of Alberta, 1993.

[3] J.-H. Yoo, C. W. Roeder, and D. E. Lehman, "Analytical Performance Simulation of Special Concentrically Braced Frames,” J. Struct. Eng., vol. 134, no. 6, pp. 881-889, 2008.

[4] J. W. Berman et al., "TRIAGE EVALUATION OF GUSSET PLATES IN STEEL TRUSS BRIDGES,” no. December, 2010.

[5] J. W. Berman et al., "Rapid Assessment of Gusset Plate Safety in Steel Truss Bridges,” J. Bridg. Eng., vol. 17, no. April, pp. 221231, 2012.

[6] J. Berman, B. Wang, C. Roeder, A. Olson, and D. Lehman, “Triage Evaluation of Gusset Plates in Steel Truss Bridges,” no. December, pp. 1-83, 2010.

[7] National Transportation Safety Board (NTSB), "Collapse of I-35W Highway Bridge Minneapolis, Minnesota August 1, 2007,” Highw. Accid. Rep., no. NTSB/HAR-08/03, p. 178, 2008.

[8] R. J. H. Holt; " “Adequacy of the U10 \& L11 Gusset Plate Designs for the Minnesota Bridge No. 9340 (I-35W over the Mississippi River)," Fed. Highw. Adm. turnerfairbank Highw. Res. Cent. Rep., vol. 9340, no. 9340, p. 20, 2008.

[9] Barry B. LePatner, "The Story Behind the Collapse of Minnesota, s I-35W Bridge on,” Univ. New Engl. Press, no. Too Big to Fall: America's Failing Infrastructure and the Way Forward, 2010.

[10] M. A. R. Lora, W. J. Wright, R. T. Leon, and C. D. Moen, "STUDY OF THE I-35W HIGHWAY BRIDGE COLLAPSE MECHANISM,” Thesis Virginia Polytech. Inst. State Univ., 2013.

[11] W. Dewobroto, Struktur Baja, Perilaku, Analisis \& Desain - AISC 2010. 2016.

[12] S. Hao and M. Asce, "I-35W Bridge Collapse,” J. Bridg. Eng., vol. 15, no. 5, pp. 608-614, 2010.

[13] M. Liao, T. Okazaki, R. Ballarini, A. E. Schultz, and T. V. Galambos, "Nonlinear Finite-Element Analysis of Critical Gusset Plates in the I35W Bridge in Minnesota,” $J$. Struct. Eng., vol. 137, no. July 15, 2010, pp. 59-68, 2010. 